\title{
$\mathrm{CeO}_{2}$ 纳米晶的制备及其在电化学上的应用*
}

\author{
董相廷 \\ (长春光学精密机械学院材料工程系, 长春 130022)
}

曲晓刚 洪广言** 于德才陆天虹 倪嘉贸

(中国科学院长春应用化学研究所, 长春 130022)

\section{关键词 $\mathrm{CeO}_{2}$ 纳米晶 溶胶 - 凝胶法 细胞色素 c 促进剂}

纳米材料的合成、结构功能特性及其应用的研究成为人们共同关注的前沿课题 ${ }^{[1,2]} . \mathrm{CeO}_{2}$ 是一种廉价而用途极广的材料, 如用于发光材料、催化剂、电子陶瓷等. 细胞色素 $\mathrm{c}$ 是一种含 血红素的金属蛋白质分子, 通过对其电化学行为的研究, 为认识生物体内的电子传递反应机 理和能量转换提供有用信息, 对于揭示生命现象的本质具有重大意义. 细胞色素 $\mathrm{c}$ 在裸金电 极上是极不可逆的, 现已发现了加速其可逆反应的多种促进剂 ${ }^{[3 \sim 9}$, 对其电化学反应机理也进 行了深人的讨论 ${ }^{[6 \sim 8]}$. 本文用溶胶 - 凝胶法合成了 $\mathrm{CeO}_{2}$ 纳米晶; 将 $\mathrm{CeO}_{2}$ 纳米晶修饰在金电极 上研究了细胞色素 $\mathrm{c}$ 的电子传递反应, 发现 $\mathrm{CeO}_{2}$ 纳米晶是一种良好的促进剂.

\section{1 样品的制备与测试}

称取一定量草酸铈 $(G R)$, 用蒸馏水调成浆状, 滴加浓 $\mathrm{HNO}_{3}(\mathrm{GR})$ 和 $\mathrm{H}_{2} \mathrm{O}_{2}(\mathrm{AR})$, 完全溶解 后加人柠檬酸 (GR), 于 $50 \sim 70^{\circ} \mathrm{C}$ 时缓慢蒸发形成溶胶, 继续加热有大量气泡产生, 并有白色 凝胶形成, 体积膨胀, 有大量棕色烟放出. 将凝胶于 $120^{\circ} \mathrm{C}$ 干燥 $12 \mathrm{~h}$, 得到淡黄色干凝胶, 将其 在不同温度下进行热处理, 即得到 $\mathrm{CeO}_{2}$ 纳米晶.

用日本理学 D/MAX-IIB 型 X 射线衍射仪进行结构分析; 用 $H-600$ 型透射电子显微镜进 行粒子形貌分析和大小测定; 用 BET 法测比表面积.

电化学测量是在美国 PAR 公司生产的 276 型恒电位仪和 179 型信号发生器上进行的, 记 录仪为 Houston 公司生产的 XY 记录仪. 实验所用的电解池为传统的三电极玻璃电解池. 工作电极为由环氧树酯所封的金棒玻璃电极, 电极的暴露面积 $0.8 \mathrm{~mm}^{2}$, 铂丝作为对电极, 参 考电极为饱和甘手电极 (SCE). 工作电极的表面修饰是将新抛光好的金电极置于 $\mathrm{CeO}_{2}$ 悬浊 液中浸泡 $35 \mathrm{~min}$, 取出后用 3 次蒸馏水清洗 2 次便可使用. 细胞色素 $\mathrm{c}$ (VI 型 $99 \%$ ) 的电化学 测量是在 $0.38 \mathrm{mmol} / \mathrm{L}$ 细胞色素 $\mathrm{c}$ 溶液中进行, 缓冲溶液为 $\mathrm{pH}=7$ 的 $0.025 \mathrm{~mol} / \mathrm{L}$ 磷酸盐溶液, 支持电解质为 $0.1 \mathrm{~mol} / \mathrm{L} \mathrm{NaClO}_{4}$ 溶液. 所有溶液均由 3 次水配制, 实验之前进行通氮气除氧. 扫描速度为 $50 \mathrm{mV} / \mathrm{s}$, 扫描电位范围为 $-0.20 \sim 0.20 \mathrm{~V}$, 文中所用电位均相对于饱和甘手电极.

1995-02-07 收稿, 1995-11-08 收修改稿

*国家自然科学基金与中国科学院稀土化学与物理开放实验室资助项目

**通讯联系人 


\section{2 结果与讨论}

\section{1 物相分析}

为了研究 $\mathrm{CeO}_{2}$ 的最低合成温度及相变化, 对干凝胶及其焙烧 $2 \mathrm{~h}$ 后的样品进行了 XRD 分析 (见图 1), 发现热处理温度低于 $230^{\circ} \mathrm{C}$ 时为无定形, $250 \sim 1000{ }^{\circ} \mathrm{C}$ 均为单相立方 $\mathrm{CeO}_{2}$ 纳 米唱, 其 $d$ 值与 JCPDS(4-0593) 所列 $d$ 值一致, 空间群为 $O_{H}^{5}-F_{M 3 M}$.

\section{2 热失重分析}

图 2 表明了干凝胶在不同温度焙烧 $2 \mathrm{~h}$ 的样品重量的变化.

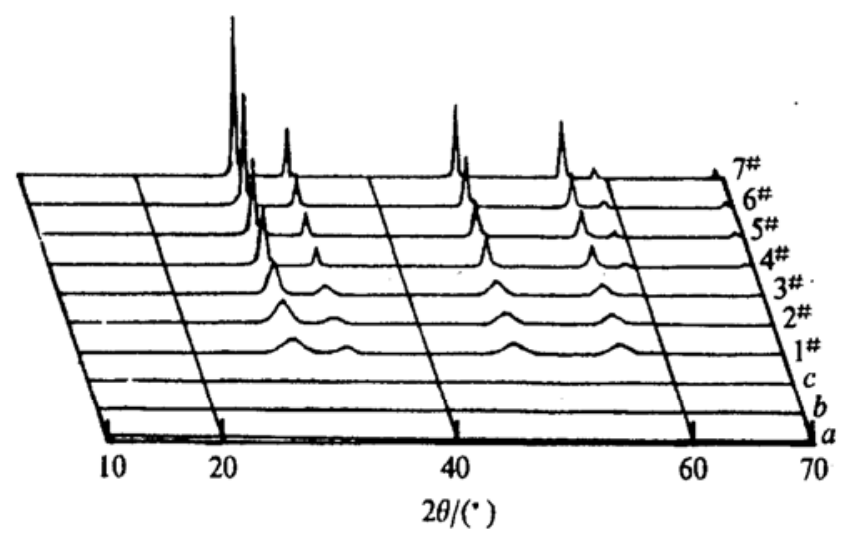

图 1 不同样品的 X-射线衍射图

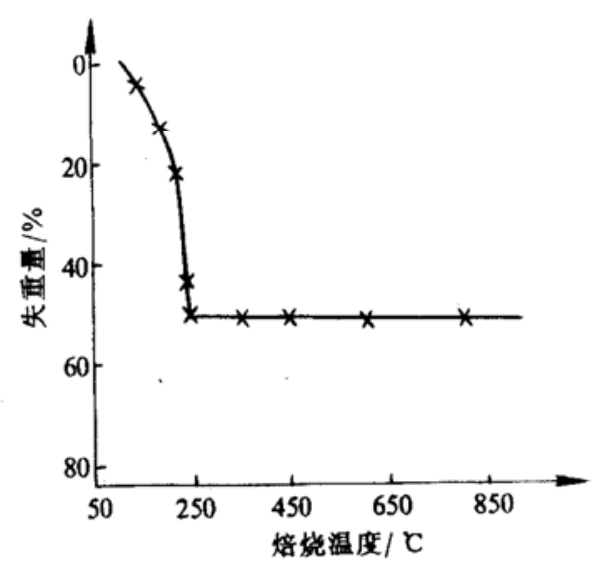

图 2 失重量与焙烧温度的关系

$\mathrm{a}-$ 干凝胶, $\mathrm{b}-210^{\circ} \mathrm{C}, \mathrm{c}-230^{\circ} \mathrm{C}, 1^{\#-}-250^{\circ} \mathrm{C}, 2^{\# \#--~}$

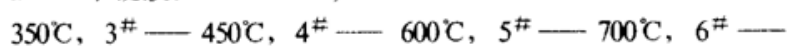

$800^{\circ} \mathrm{C}, 7^{\ddagger}-1000^{\circ} \mathrm{C}$

从图 2 可见, 在 $250{ }^{\circ} \mathrm{C}$ 以前, 随焙烧温度的增加, 烧失量明显增加; $250 \sim 800{ }^{\circ} \mathrm{C}$ 时烧失量 略有增加, 没有较明显的失重, 说明 $250^{\circ} \mathrm{C}$ 时分解反应基本结束.

\section{$2.3 \mathrm{CeO}_{2}$ 粒子形貌与粒径}

电子显微镜测试表明, $\mathrm{CeO}_{2}$ 粒子基本呈球形; 粒子大小与焙烧温度有关, 如图 3 所示.

从图 3 可见, 随焙烧温度的升高, $\mathrm{CeO}_{2}$ 粒径呈指数增加. 从图 4 可见, 随焙烧温度的增

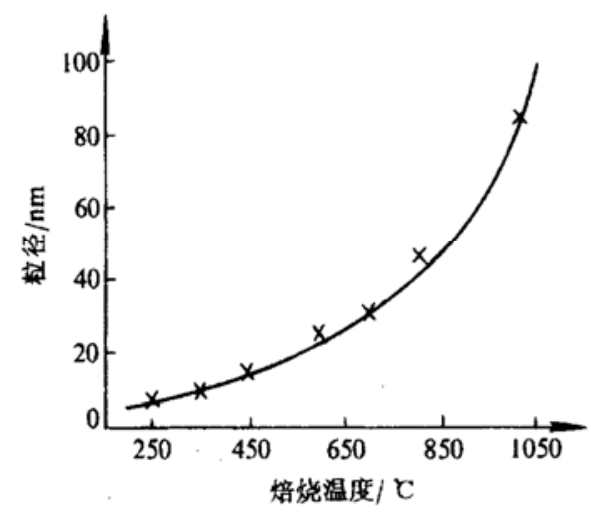

图 $3 \mathrm{CeO}_{2}$ 粒径随焙烧温度的变化

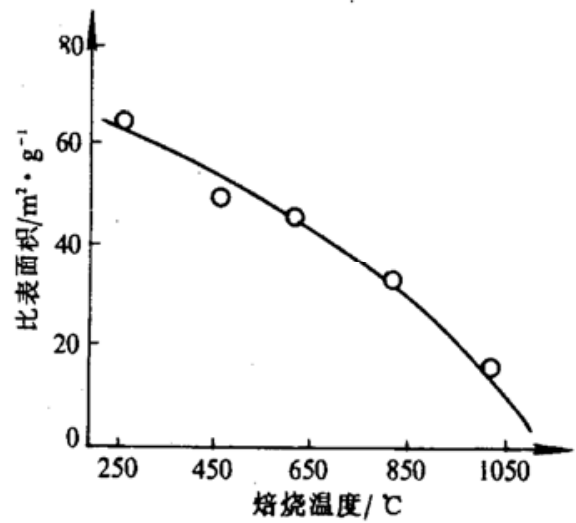

图 $4 \mathrm{CeO}_{2}$ 的比表面积与焙烧温度的关系 
加, 粒径增大, $\mathrm{CeO}_{2}$ 纳米晶的比表面积减小.

\section{$2.4 \mathrm{CeO}_{2}$ 纳米晶对细胞色素 $\mathrm{c}$ 电化学反应促进作用及其稳定性的研究}

众所周知, 细胞色素 $\mathrm{c}$ 分子不能在裸金电极上进行快速的电子传递反应 (见图 5 中曲线 a), 然而在 $\mathrm{CeO}_{2}$ 纳米晶修饰的金电极上, 细胞色素 $\mathrm{c}$ 却可以进行快速的电子传递反应. 由于 $\mathrm{CeO}_{2}$ 粒子在所研究的电位范围内 $(-0.20 \sim 0.20 \mathrm{~V})$ 并不发生任何电化学反应, 所以图 5 中 (曲 线 $\mathrm{b}, \mathrm{c}, \mathrm{d})$ 的电化学反应是由细胞色素 $\mathrm{c}$ 分子引起的.

图 5 中曲线 $\mathrm{b}$ 阴、阳极反应峰电位差为 $70 \mathrm{mV}$ 左右, 中点值为 $0.01 \mathrm{~V}$, 非常接近于细胞色 素 $\mathrm{c}$ 的金电极电位 ${ }^{\circledR}$, 阴极峰电流与阳极峰电流之比接近于 1 . 我们测定了不同扫描速度时细 胞色素 $\mathrm{c}$ 的循环伏安曲线, 将峰电流对扫描速度的平方根作图则得到一条直线, 上述这些性质 表明细胞色素 $\mathrm{c}$ 在 $\mathrm{CeO}_{2}$ 纳米晶修饰金电极上发生了一个由扩散控制的准可逆直接电化学反 应, 而且 $\mathrm{CeO}_{2}$ 纳米晶的促进作用十分稳定. 图 6 给出了第 1 圈扫描和连续第 25 圈扫描时, 细 胞色素 $\mathrm{c}$ 的循环伏安曲线.

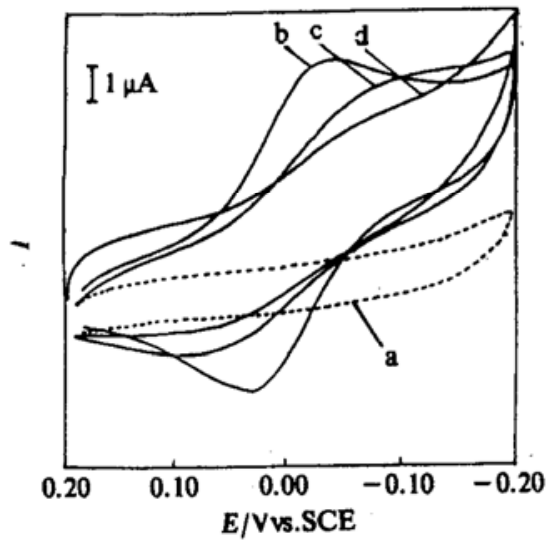

图 5 不同 $\mathrm{CeO}_{2}$ 粒径时细胞色素 $\mathrm{c}$ 的循环伏安 曲线

$\mathrm{a}-$ 无 $\mathrm{CeO}_{2}, \mathrm{~b}-8 \mathrm{~nm}\left(1^{\#}\right), \mathrm{c}-45 \mathrm{~nm}\left(6^{\#}\right)$, $\mathrm{d}-85 \mathrm{~nm}\left(7^{\#}\right)$

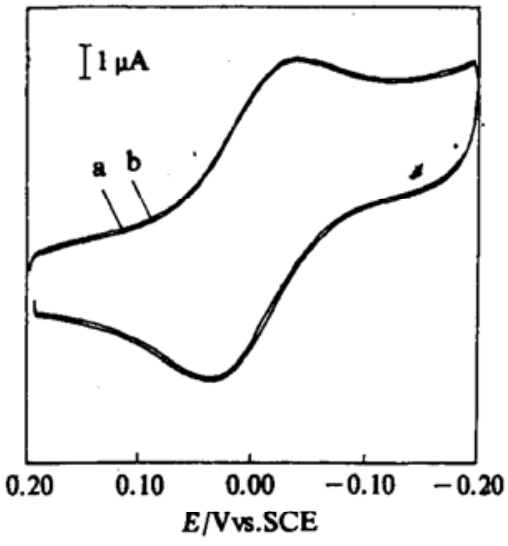

图 6 不同循环次数对细胞色素 $\mathrm{c}$ 电化学反应的 影响 $\left(\mathrm{CeO}_{2}\right.$ 粒径为 $8 \mathrm{~nm}\left(1^{\#}\right)$

$\mathrm{a}$ 一第 1 圈, b- 第 25 圈

从图 6 可见, 峰电流及峰电位差基本没有改变, 说明 $\mathrm{CeO}_{2}$ 纳米晶的促进作用十分稳定. 从图 5 也可以看出, $\mathrm{CeO}_{2}$ 粒度不同, 促进效果也不同, 且粒度越小, 促进效果越好. 表 1 列出 了相同条件下 $\mathrm{CeO}_{2}$ 粒度与细胞色素 $\mathrm{c}$ 循环伏安图中阴、阳极反应峰电位差之间的关系.

从表 1 可见, 随 $\mathrm{CeO}_{2}$ 粒度的减小, 阴、阳极反应峰电位差也减小, 即对细胞色素 $\mathrm{c}$ 电化学

表 $1 \mathrm{CeO}_{2}$ 粒度与细胞色素 $\mathrm{c}$ 循环伏安曲线中阴、阳极反 应峰电位差之间的关系

\begin{tabular}{cccccc}
\hline 样品 & $1 \#$ & $3 \#$ & $4 \#$ & $6 \#$ & $7 \#$ \\
\hline 粒径 $/ \mathrm{nm}$ & 8 & 15 & 23 & 45 & 85 \\
$\Delta E_{\mathrm{p}} / \mathrm{mV}$ & 70 & 80 & 90 & 100 & 110 \\
\hline
\end{tabular}

反应的促进效果越好.

当金电极修饰有 $\mathrm{CeO}_{2}$ 粒子后, $\mathrm{CeO}_{2}$ 粒子中的界面氧原子将与细胞色素 c 中 赖氨酸残基上的质子化氨基相互作用形 成氢键, 并且普遍认为这种相互作用才有 可能形成细胞色素 $\mathrm{c}$ 与电极之间的电子

传递反应通道. $\mathrm{CeO}_{2}$ 粒子是一种半导体材料, 因而当该粒子吸附在金电极表面上时, 将在电 极表面形成许多电化学活性点, 从而构成了电极与细胞色素 $\mathrm{c}$ 之间的电子传递反应通道, 这样 
才可以获得细胞色素 $\mathrm{c}$ 的快速电子传递反应. 当 $\mathrm{CeO}_{2}$ 粒子越小时, 比表面积就越大, 界面氧 原子数就越多, 因此在电极表面将产生更多的电化学活性点, 尽管采用与较大粒子相同的修 饰时间,却可以获得更好的促进效果.

\section{3 结论}

用溶胶 - 凝胶法合成了 $\mathrm{CeO}_{2}$ 纳米晶, 均属于立方晶系, 空间群为 $O_{H}^{5}-F_{M 3 M}, \mathrm{CeO}_{2}$ 粒径随焙 烧温度的增加而增大, 比表面积则随焙烧温度的升高而减小.

$\mathrm{CeO}_{2}$ 纳米晶是细胞色素 $\mathrm{c}$ 电化学反应的良好促进剂, 且促进作用很稳定.

\section{参 考 文 献}

1 Brus L E, Siegel R W, Gronsky R et al. Research opportunities on clusters and cluster-assembled materials. J Mater Res, 1989, 4(3): 704 736

2 Hayashi C. Ultrafine particles. J Vac Sci Tech, 1987, A5(4): $1375 \sim 1384$

3 Hinnen C, Parsons R. Electrochemical and spectroreflectance studies of the adsorbed horse heart cytochrome c and cytochrome $C_{3}$ from D. vulgaris, miyazaki strain at gold electrode. J Electroanal Chem, 1983, 147: 329 337

4 Qu X G, Lu T H, Dong S f. Electrochemical reaction of cytochrome c at gold electrodes modified with thiophene containing one functional group. Bioelectro Bioenerg, 1994, 34: 153 156

5 Lu T H, Yu X J, Dong S J. Direct electrochemical reactions of cytochrome c at iodide-modified electrodes. J Electroanal Chem, 1994, 369: 79 86

6 Allen P M, Allen H, Hill O et al. Surface modifiers for the promotion of direct electrochemistry of cytochrome c. J Electroanal Chem, 1984, 178: 69 86

7 Bond $\mathrm{A} \mathrm{M}$, Allen $\mathrm{H}$, Hill $\mathrm{O}$ et al. Investigation of the mass transport process in the voltammetry of cytochrome c at 4, 4'-bipyridyl disulfide modified stationary and rotated macro- and microdisk gold electrodes. J Phys Chem, 1992, 96: $8100 \sim 8105$

8 Albery W J, Eddowes M J, Allen $\mathrm{H}$ et al. Mechanism of the reduction and oxidation reaction of cytochrome c at a modified gold electrode. J Am Chem Soc, 1981, 103: $3904 \sim 3910$ 